\title{
Investigation of monoterpenoid resistance mechanisms in Pseudomonas putida and their consequences for biotransformations
}

\author{
Florence Miramella Schempp ${ }^{1,2} \cdot$ Katharina Elisabeth Hofmann ${ }^{1} \cdot \mathrm{Jia} \mathrm{Mi}^{1} \cdot$ Ferdinand Kirchner $^{1} \cdot$ Annika Meffert $^{1}$. \\ Hendrik Schewe ${ }^{1}$. Jens Schrader ${ }^{1}$ • Markus Buchhaupt ${ }^{1}$
}

Received: 20 January 2020 / Revised: 5 March 2020 / Accepted: 20 March 2020 / Published online: 16 April 2020

(C) The Author(s) 2020

\begin{abstract}
Monoterpenoids are widely used in industrial applications, e.g. as active ingredients in pharmaceuticals, in flavor and fragrance compositions, and in agriculture. Severe toxic effects are known for some monoterpenoids making them challenging compounds for biotechnological production processes. Some strains of the bacterium Pseudomonas putida show an inherent extraordinarily high tolerance towards solvents including monoterpenoids. An understanding of the underlying factors can help to create suitable strains for monoterpenoids de novo production or conversion. In addition, knowledge about tolerance mechanisms could allow a deeper insight into how bacteria can oppose monoterpenoid containing drugs, like tea tree oil. Within this work, the resistance mechanisms of $P$. putida GS1 were investigated using selected monoterpenoid-hypertolerant mutants. Most of the mutations were found in efflux pump promoter regions or associated transcription factors. Surprisingly, while for the tested monoterpenoid alcohols, ketone, and ether high efflux pump expression increased monoterpenoid tolerance, it reduced the tolerance against geranic acid. However, an increase of geranic acid tolerance could be gained by a mutation in an efflux pump component. It was also found that increased monoterpenoid tolerance can counteract efficient biotransformation ability, indicating the need for a fine-tuned and knowledge-based tolerance improvement for production strain development.

Key points

- Altered monoterpenoid tolerance mainly related to altered activity of efflux pumps.

- Increased tolerance to geranic acid surprisingly caused by decreased export activity.

- Reduction of export activity can be beneficial for biotechnological conversions.
\end{abstract}

Keywords Pseudomonas putida GS1 · Monoterpenes · Monoterpenoids · Resistance · Tolerance $\cdot$ Ttg efflux pumps

\section{Introduction}

Monoterpenoids are a class of natural products containing more than 1000 different substances (Breitmaier 2005). All contain a linear, cyclic, or bicyclic $\mathrm{C}_{10}$ backbone

Electronic supplementary material The online version of this article (https://doi.org/10.1007/s00253-020-10566-3) contains supplementary material, which is available to authorized users.

Markus Buchhaupt

markus.buchhaupt@dechema.de

1 DECHEMA-Forschungsinstitut, Industrial Biotechnology, Theodor-Heuss-Allee 25, 60486 Frankfurt am Main, Germany

2 Faculty Biological Sciences, Goethe University Frankfurt, Max-von-Laue-Str. 9, 60438 Frankfurt am Main, Germany
(Habermehl et al. 2008) forming different hydrocarbons or oxygenated compounds (Berger 2007; Schrader and Bohlmann 2015). In nature, monoterpenoids are ubiquitously present in plants, e.g., in essential oils of coniferous wood, in citrus fruits, and in flowers (Schrader 2010). In industry, monoterpenoids are widely used in pharmaceuticals, flavor and fragrance, and agriculture (Habermehl et al. 2008; Chen et al. 2015). However, for many monoterpenoids, the extraction from natural sources poses challenges low concentration in the raw material or because the natural sources are constantly ceasing. Furthermore, many of the structurally more complex terpenoids cannot be chemically synthesized in an economic way. Therefore, microbial production or conversion processes can provide attractive alternatives, particularly if regioselective or stereoselective reactions are included (Berger 2007; Chen et al. 2015). 
Monoterpenoids have certain physicochemical characteristics that impede the development of industrial bioprocesses dealing with such compounds as educts and/or products: poor water solubility, high volatility, and distinct cytotoxicity (Trombetta et al. 2005; Berger 2007; Schrader 2010). The latter is related to their accumulation in the cell membrane, leading to an increased membrane fluidity and disturbance of essential cellular functions. In addition, protein denaturation and oxidative damage are caused by incubation of cells with certain monoterpenoids (Andrews et al. 1980; Uribe et al. 1985; Sikkema et al. 1994; Trombetta et al. 2005; Schrader 2010).

It is known that certain microorganisms, among others some strains of Pseudomonas putida, can cope with high concentrations of organic solvents (Ramos et al. 2015), including monoterpenoids (Speelmans et al. 1998; Mi et al. 2014). P. putida is a gram-negative, saprotrophic soil bacterium (Nelson et al. 2002; Silby et al. 2011) with a diverse catabolism, including the ability to degrade different organic solvents (Timmis 2002; Wu et al. 2011; Ramos et al. 2015). Several P. putida-based biotechnological production processes for monoterpenoids have been described, such as the biotransformation of limonene to perillic acid (Speelmans et al. 1998; Mars et al. 2001) or perillyl alcohol (van Beilen et al. 2005; Cornelissen et al. 2011; Cornelissen et al. 2013), the de novo synthesis of geranic acid starting from glycerol (Mi et al. 2014), or the regioselective and stereoselective hydroxylation of 1,8 cineole to (1R)-6ß-hydroxy-1,8-cineole (Mi et al. 2016).

To further increase the native monoterpenoid tolerance of P. putida and to enable the transfer of underlying resistance mechanisms to suitable host strains for biotechnological production processes, the molecular factors of monoterpenoid tolerance and potential specificities for certain structural elements have to be determined. The general solvent tolerance mechanisms in P. putida have been studied intensively with a focus on the model compounds toluene or butanol, reviewed previously (Isken and de Bont 1998; Ramos et al. 2002; Ramos et al. 2015). The multifactorial response after solvent exposure involves changes in membrane composition (Pinkart and White 1997; Ramos et al. 1997; Isken and de Bont 1998; Heipieper et al. 2003), activation of a general stress response system, enhanced energy generation (Ramos et al. 2015), and induction of specific efflux pumps that extrude solvents to the medium (Isken and de Bont 1996; Ramos et al. 1997; Kieboom et al. 1998). In P. putida DOT-T1E, three RND (resistance-nodulation-division) efflux systems have been identified to be directly involved in solvent tolerance (Ramos et al. 2015). These efflux systems (TtgABC, TtgDEF, and TtgGHI) are encoded by the so-called toluene tolerance genes (Ramos et al. 1998; Mosqueda and Ramos 2000; Duque et al. 2001; RodríguezHerva et al. 2007). All three efflux pumps consist of three components: an inner membrane protein $(\mathrm{Ttg} \mathrm{B} / \mathrm{E} / \mathrm{H})$, which binds the substrates and acts as the extrusion element, an outer membrane protein that reaches into the periplasmic space to form a channel $(\mathrm{Ttg} \mathrm{C} / \mathrm{F} / \mathrm{I})$, and a lipoprotein that plays a role in stabilizing the interaction between the other two elements ( $\operatorname{Ttg} \mathrm{A} / \mathrm{D} / \mathrm{G})$ (Ramos et al. 2002). The Ttg pump-mediated efflux is energized by the proton motive force across the cytoplasmic membrane (Udaondo et al. 2012; Ramos et al. 2015). Expression of the $t \operatorname{tg}$ operons is repressed by the transcription factors $\mathrm{TtgR}, \mathrm{Ttg} \mathrm{T}$, and $\mathrm{TtgV}$, which are encoded adjacent to the $t t g$ efflux pump operons (Duque et al. 2001; Ramos et al. 2002; Rojas et al. 2003; Teran et al. 2003; Ramos et al. 2005; Krell et al. 2007; Terán et al. 2007; Ramos et al. 2015). In other Pseudomonas strains, similar tolerance mechanisms have been described, such as the SrpABC efflux pump in P. putida S12 (Isken and de Bont 1996; Kieboom et al. 1998) or the Mex efflux systems in Pseudomonas aeruginosa (Poole et al. 1993; Gotoh et al. 1995; Poole et al. 1996). Whether these general solvent resistance mechanisms of $P$. putida also apply to monoterpenes and monoterpenoids remains to be investigated.

In vitro studies by Sikkema et al. (1994) and experiments with Escherichia coli by Trombetta et al. (2005) have shown that the toxic effect of monoterpenes and their derivatives is at least partially caused by the incorporation of the substances into the bacterial cell membranes, whereby the function of the membranes is disturbed. In addition, they probably also penetrate the cells and interact with other targets, such as enzymes (Sikkema et al. 1994; Trombetta et al. 2005). With regard to tolerance mechanisms, the MexAB-OprM efflux pump of $P$. aeruginosa was shown to play a decisive role for the tolerance of this species to tea tree oil and its monoterpenoid compounds (Papadopoulos et al. 2008). The Mex efflux systems of $P$. aeruginosa are very similar to the Ttg and Srp efflux pumps of P. putida (Ramos et al. 2002). In addition, other studies with $E$. coli revealed that active efflux of monoterpenoids is an important factor for increased tolerance (Dunlop et al. 2011). These studies let us expect an involvement of $P$. putida efflux systems in monoterpenoid tolerance.

To test this hypothesis and to identify and further characterize mechanisms specifically responsible for the natural high tolerance of $P$. putida GS1 towards several monoterpenoids, we selected monoterpenoid-hypertolerant mutants and characterized them via genome sequencing, deletion and complementation experiments, tolerance assays, qPCRs, and efflux activity measurements. Moreover, the impact of increased monoterpenoid tolerance on a biotechnological production process was investigated.

\section{Materials and methods}

\section{Chemicals and media}

All chemicals were purchased from Sigma-Aldrich (Taufkirchen, Germany), Carl-Roth (Karlsruhe, Germany), or Merck Millipore (Darmstadt, Germany). 
Monoterpenoids were acquired with different purities: 1,8cineole ( $\geq 99 \%)$, citral $(\geq 98 \%$ ), geranic acid $(\geq 85 \%)$, geraniol $(\geq 99 \%)$, geranyl acetate $(\geq 99 \%)$, geranyl formate $(\geq 95 \%)$, linalool $(\geq 97 \%)$, myrcene $(\geq 95 \%), \alpha$-terpinene $(\geq 95 \%), \gamma$ terpinene $(\geq 98.5 \%)$, (+)-terpinen-4-ol $(\geq 98.5 \%),(+)-\alpha$-terpineol $(\geq 97 \%), \alpha$-terpinyl acetate $(\geq 97 \%)$, and $(1 S)-(-)$ verbenone $(\geq 99 \%)$.

For cultivation of E. coli and P. putida, lysogeny broth (LB) or terrific broth (TB) medium was used. For solid media, $17 \mathrm{~g} \mathrm{l}^{-1}$ agar-agar was added. Antibiotics and other supplements were used at the following concentrations, if required: kanamycin $(\mathrm{Km}) 50 \mu \mathrm{g} \mathrm{ml}^{-1}$, gentamicin $(\mathrm{Gm}) 25 \mu \mathrm{g} \mathrm{ml}^{-1}$, tetracycline (Tet) $50-150 \mu \mathrm{g} \mathrm{ml}^{-1}$, and L-rhamnose $2 \mathrm{mg} \mathrm{ml}^{-1}$.

\section{Strains, plasmids, and oligonucleotides}

All strains, plasmids, and oligonucleotides used in this study are listed in Online Resource Table S1.

P. putida cells were routinely grown at $30^{\circ} \mathrm{C}$ and $E$. coli cells at $37^{\circ} \mathrm{C}$. All oligonucleotides were ordered from SigmaAldrich (Taufkirchen, Germany).

\section{Strain and plasmid construction}

Deletion mutants of $\operatorname{tg} R$, $\operatorname{tg} T$, and 10 nucleotides of $\operatorname{tg} A B C$ 5 '-UTR were obtained following the method published by Martínez-García and de Lorenzo (2011). For this purpose, plasmids pEMG- $\Delta \operatorname{ttg} R$, pEMG- $\Delta \operatorname{tg} T$, and pEMG- $\Delta 10 \mathrm{nt}-$ $\operatorname{ttg} A B C$ were constructed using primer $\mathrm{P} 1-\mathrm{P} 4$, P5-P8, or P9-P12, respectively. The correct deletion was checked by colony PCR and sequencing of the obtained PCR fragments.

Plasmids pMiS4-ttgR and pMiS4-ttg $T$ were constructed by amplifying the $\operatorname{tg} R$ and the $\operatorname{tg} T$ genes together with their native promoter regions via PCR using $P$. putida GS1 gDNA as template and primer P13 and P14 or P15 and P16, respectively.

All plasmids used in this study were constructed using Gibson isothermal assembly (Gibson et al. 2009) and chemical competent $E$. coli cells (Inoue et al. 1990). The correct and sequenced plasmids were electroporated into P. putida GS1 strains following a protocol by Choi et al. (2006).

\section{Generation of mutant library}

Transposon mutagenesis of $P$. putida GS1 was performed following methods published by Klebensberger et al. (2007) and $\mathrm{Li}$ et al. (2010). Introduction of plasmid pALMAR-3, harboring a Himarl mariner transposon (Lampe et al. 1999), into $P$. putida GS1 was performed by bi-parental mating with E. coli $\mathrm{S} 17-1 \lambda$ pir as donor. For $E$. coli $\mathrm{S} 17-1 \lambda$ pir harboring pALMAR-3, $20 \mathrm{ml} \mathrm{LB}$ medium containing $30 \mathrm{\mu g} \mathrm{ml}^{-1}$ kanamycin was inoculated with an $\mathrm{OD}_{600}$ of 0.1 from an overnight pre-culture. For P. putida GS1, $100 \mathrm{ml} \mathrm{LB}$ medium was inoculated with an $\mathrm{OD}_{600}$ of 0.05 . After reaching $\mathrm{OD}_{600}$ of 2 or 0.3 , respectively, $8 \mathrm{ml}$ of LB culture of the $E$. coli donor strain and $100 \mathrm{ml}$ of the recipient strain P. putida GS1 were harvested, washed twice with $8 \mathrm{ml}$ pre-warmed LB medium, and resuspended in $400 \mu 1$ pre-warmed LB medium each. Subsequently, the cell suspensions were mixed in a $1: 1$ volume ratio (cell ratio E. coli to $P$. putida around 1:2) and placed on LB agar. After incubation for $24 \mathrm{~h}$ at $30^{\circ} \mathrm{C}$, the cells were resuspended from the plate with $2 \mathrm{ml} 0.9 \%(w / v) \mathrm{NaCl}$ solution. One hundred microliter aliquots of the cell suspension were spread on Pseudomonas isolation agar plates (King et al. 1954) containing $150 \mu \mathrm{g} \mathrm{ml}^{-1}$ tetracycline to select for P. putida transposon mutants. After incubation for $24 \mathrm{~h}$ at $30{ }^{\circ} \mathrm{C}$, colonies were washed from the plates with $2 \mathrm{ml} \mathrm{LB}$ medium containing $20 \%$ glycerol and stored at $-80^{\circ} \mathrm{C}$.

\section{Growth selection of monoterpenoid-hypertolerant mutants}

For growth selection under different monoterpenoid stress conditions, both P. putida GS1 wildtype (WT) cells and the transposon mutant library were used as a mixture to ensure large cell variety at the starting point. The monoterpenoids were added directly to the bacteria cultures in different, partly increasing concentrations: 1,8 -cineole 20,40 , and $60 \mathrm{mM}$; geranic acid 35 and $90 \mathrm{mM}$; geraniol 32 and $65 \mathrm{mM}$; $\alpha$ terpineol $17.5 \mathrm{mM}$; and verbenone $35 \mathrm{mM}$. The cryo stocks were thawed on ice and grown overnight at $30{ }^{\circ} \mathrm{C}$ in shake flasks with $20 \mathrm{ml} \mathrm{TB}$ medium containing $50 \mu \mathrm{g} \mathrm{ml}^{-1}$ tetracycline.

For the selection of 1,8-cineole-hypertolerant mutants, the preculture was diluted to an $\mathrm{OD}_{600}$ of 0.1 with $\mathrm{TB}$ medium. The cells were cultivated with the stressor for $24 \mathrm{~h}$ at $30{ }^{\circ} \mathrm{C}$ in a microbioreactor system (BioLector $\left.{ }^{\circledR}\right)$ at $1000 \mathrm{rpm}$ using $1.5 \mathrm{ml}$ culture volume in 48-well Flowerplates ${ }^{\circledR}$ (m2p-labs $\mathrm{GmbH}$, Baesweiler, Germany) covered by gas-permeable sealing foil. From the stationary phase culture, new TB cultures were inoculated to an $\mathrm{OD}_{600}$ of 0.1 and again cultivated in the microbioreactor system with 1,8-cineole. This procedure was followed for five cultivation steps. After each round, cultures with improved tolerance properties were selected for the next selection round. Each culture was cultivated in triplicates. Only for the first cultivation $50 \mu \mathrm{g} \mathrm{ml}^{-1}$ tetracycline was added to the medium. After cultivation 2, 3, and 4, the cells were spread on LB-agar plates and incubated over night at $30{ }^{\circ} \mathrm{C}$ or for 3 days at room temperature. Subsequently, the cells were washed from the agar plates with $3 \mathrm{ml} \mathrm{NaCl}(0.9 \%)$, and $1 \mathrm{ml}$ of the cell suspension was used to inoculate the new culture.

For the selection of geranic acid, geraniol, $\alpha$-terpineol, and verbenone-hypertolerant mutants $200 \mu$ l preculture was transferred into $20 \mathrm{ml} \mathrm{TB}$ medium each and the respective stressor 
was added. The cultures were incubated in shake flasks for around $24 \mathrm{~h}$ at $30^{\circ} \mathrm{C}$. Between five and seven sequential cultivation rounds were conducted for each monoterpenoid. For each further round, the main culture was inoculated to a start $\mathrm{OD}_{600}$ of 0.1. Before the last cultivation round for all monoterpenoids, the cells were spread out on LB agar to obtain single colonies for inoculation.

Based on the growth performance of the different mutants in the last cultivation round, for each selection substance one (or in the case of verbenone two) candidate strains were selected for further characterization.

\section{Genetic characterization of monoterpenoid-hypertolerant mutants}

In order to determine the genotype of the selected mutant strains, the mutation sites were mapped via splinkerette PCR (Devon et al. 1995; Mikkers et al. 2002) (CR mutant) or genome sequencing (TR, GR, GAR, VR1, VR2 mutant).

For the 1,8-cineole selected mutant (CR), gDNA was extracted using the GenElute Bacterial Genomic DNA kit (Sigma-Aldrich, Taufkirchen, Germany). Of total gDNA, $1.5 \mu \mathrm{g}$ was digested with BamHI. Subsequently, hybridized splinkerette adapter (P17 and P18, $1.2 \mathrm{pmol}$ ) was ligated to $300 \mathrm{ng}$ of the DNA fragments using T4-Ligase (NEB, Frankfurt am Main, Germany). Ligation products were isolated using the DNA Clean \& Concentrator ${ }^{\mathrm{TM}_{-} 5}$ kit (Zymo Research, Freiburg, Germany). Transposon-chromosome junctions were amplified by PCR with a primer specific for the adapter (P19) and a primer specific for the mariner transposon (P20). After purification of the PCR product with the DNA Clean \& Concentrator ${ }^{\mathrm{TM}}-5$ kit (Zymo Research, Freiburg, Germany), a second PCR with the first PCR product as template using primer P21 and P22 was conducted. Finally, the obtained PCR product was purified as described before and sequenced.

To localize the transposon integration site, the sequences adjacent to the transposon were mapped to the genome sequence of P. putida GS1. The latter was provided by the company GenXPro (Frankfurt am Main, Germany) using the SMRT method and with the annotation software Prokka (v1.11) (Torsten Seemann 2014).

For the genotypic characterization of the mutants GAR, GR, TR, VR1, and VR2, for each strain, $200 \mathrm{ml} \mathrm{TB}$ medium was inoculated to an $\mathrm{OD}_{600}$ of 0.2 from an overnight culture and incubated at $30{ }^{\circ} \mathrm{C}$ and $180 \mathrm{rpm}$. When cultures reached an $\mathrm{OD}_{600}$ between 2.5 and 5, cells were harvested, washed with $20 \mathrm{ml} \mathrm{H}_{2} \mathrm{O}$, and frozen with liquid nitrogen to store at $-80^{\circ} \mathrm{C}$. Genomic DNA preparation and genome sequencing via SBS (sequencing by synthesis)-Illumina approach (Illumina, San Diego, USA) was conducted by the company GenXPro (Frankfurt am Main, Germany). Reads obtained from sequencing were mapped against the $P$. putida $\mathrm{GS} 1$ genome using the software Geneious (Biomatters Ltd., Auckland, New Zealand). In order to reduce errors occurring from the sequencing method, the P. putida GS1 WT genome was resequenced in parallel with the Illumina approach.

\section{Monoterpenoid tolerance assays}

Pre-cultures of $P$. putida GS1 WT and mutant strains grown in TB medium were used to inoculate $\mathrm{TB}$ cultures to an $\mathrm{OD}_{600}$ of 0.1 , supplemented with appropriate antibiotics if required. The respective monoterpenoid was added directly after inoculation. The concentrations tested for each compound, without consideration of purity, were 1,8-cineole $40,60,100$, and $200 \mathrm{mM}$; citral 25 and $100 \mathrm{mM}$; geranic acid 100 and $200 \mathrm{mM}$ of substance with $85 \%$ geranic acid; geraniol 40 , 65 , and $100 \mathrm{mM}$; geranyl acetate 25 and $100 \mathrm{mM}$; geranyl formate 25 and $100 \mathrm{mM}$; linalool 25 and $100 \mathrm{mM}$; myrcene $17.5,35,60,100$, and $200 \mathrm{mM}$; $\alpha$-terpinene 25 and $200 \mathrm{mM}$; $\gamma$-terpinene 17.5, 35, 60, 100, and $200 \mathrm{mM}$; (+)-terpinen-4-ol $80 \mathrm{mM}$; (+)- $\alpha$-terpineol 17.5, 35, and $60 \mathrm{mM} ; \alpha$-terpinyl acetate 25 and $100 \mathrm{mM}$; (1S)-(-)-verbenone 15,25 , and $35 \mathrm{mM}$.

Cells exposed to the different chemicals were incubated for $48 \mathrm{~h}$ at $30^{\circ} \mathrm{C}$ in a microbioreactor system (BioLector ${ }^{\circledR}$ ) at $1000 \mathrm{rpm}$ and $85 \%$ humidity using $1 \mathrm{ml}$ culture volume in 48 well Flowerplates ${ }^{\circledR}(\mathrm{m} 2 \mathrm{p}$-labs $\mathrm{GmbH})$ covered with gaspermeable sealing foil. Biomass formation was monitored via scattered light signal intensity at $620 \mathrm{~nm}$. If the strains contained the pMiS4-eGFP plasmid, growth was monitored additionally via GFP fluorescence signal intensity, using an excitation filter of $488 \mathrm{~nm}$ and an emission filter of $520 \mathrm{~nm}$. For induction of GFP expression, L-rhamnose was added to a final concentration of $0.2 \%(w / v)$ directly after inoculation. All growth comparison experiments in Flowerplates ${ }^{\circledR}$ were performed at least in triplicates. Culture samples were distributed randomly on the plate.

For quantification of verbenone concentration in the cell suspensions and in cell-free medium over time, cells were cultivated as described above but with $1.5 \mathrm{ml}$ culture volume. Verbenone $(35 \mathrm{mM})$ was added at inoculation. Samples of $180 \mu \mathrm{l}$ were taken at time points $t=0,15,22,40$, and $45 \mathrm{~h}$. To the samples, $20 \mu \mathrm{l} 1 \mathrm{M} \mathrm{H}_{2} \mathrm{SO}_{4}$ was added and analytes were extracted using $200 \mu \mathrm{l}$ ethyl acetate. Samples were centrifuged $(16,000 \times g, 2 \mathrm{~min})$, and the organic phase was analyzed by GC-MS (GC-17A with QP5050A detector, Shimadzu $)$ with a VB-5 column $(30 \mathrm{~m} \times 0.25 \mathrm{~mm} \times$ $0.25 \mu \mathrm{m}$, ValcoBond ${ }^{\circledR}$ (Valco Instruments Co. Inc. and VICI AG)). Measurements were conducted as follows: helium as carrier gas, split ratio 35 , injections at $250^{\circ} \mathrm{C}$, and a column flow of $2.6 \mathrm{ml} \mathrm{min}^{-1}$. The column temperature was programmed as follows: $80{ }^{\circ} \mathrm{C}$ for $3 \mathrm{~min}, 7^{\circ} \mathrm{C} \mathrm{min}{ }^{-1}$ up to $150^{\circ} \mathrm{C}$ followed by $150{ }^{\circ} \mathrm{C}$ for $2 \mathrm{~min}$. Absolute concentration of verbenone was calculated from chromatogram peak areas by comparison to a calibration curve prepared by measuring a 
dilution series of verbenone standard with known concentrations.

\section{RNA extraction, cDNA synthesis, and quantitative polymerase chain reaction}

In order to quantify differences in expression of the efflux pump genes between $P$. putida GS1 WT and mutants, total RNA was harvested from growing cultures following a protocol modified from Otto et al. (2019). Therefore, pre-cultures grown in TB medium were used to inoculate TB medium to an $\mathrm{OD}_{600}$ of 0.1 . Cultures were cultivated at $30^{\circ} \mathrm{C}$ and $200 \mathrm{rpm}$ until mid-exponential growth phase $\left(\mathrm{OD}_{600} 0.9-1.1\right)$. Samples of $1 \mathrm{ml}$ cell suspension were harvested $(13,000 \times \mathrm{g}, 2 \mathrm{~min})$, resuspended in $800 \mu \mathrm{l} R N A / D N A S h i e l d$ solution (Zymo Research Europe $\mathrm{GmbH}$ ), and stored at $-80^{\circ} \mathrm{C}$ until further analysis. RNA was extracted from cells using Quick $R N A^{\mathrm{TM}}$ Miniprep Plus Kit (Zymo Research Europe GmbH) following manufacturer's instructions including in-column DNase treatment. cDNA was prepared from purified RNA using the IScript $^{\mathrm{TM}}$ gDNA Clear cDNA Synthesis Kit (Bio-Rad Laboratories, Inc.). The expression levels of different efflux pump genes were analyzed using primers designed by an online Realtime PCR tool (http://www.idtdna.com/scitools/ Applications/RealTimePCR). Primers are listed in Table S1 (P23-34). As reference gene, rpoD was used and amplified with primers described previously (Franden et al. 2018). Quantitative PCR was performed using QuantiTec SYBR Green PCR Kit (Qiagen) on a PikoReal ${ }^{\mathrm{TM}}$ Real-Time PCR System (Thermo Scientific). The reaction conditions were $15 \mathrm{~min}$ at $95^{\circ} \mathrm{C}, 45 \times\left(15 \mathrm{~s}\right.$ at $94{ }^{\circ} \mathrm{C}, 30 \mathrm{~s}$ at $60{ }^{\circ} \mathrm{C}$, and $30 \mathrm{~s}$ at $\left.72{ }^{\circ} \mathrm{C}\right)$, followed by melting curve analysis $(30 \mathrm{~s} \mathrm{starting}$ at $50{ }^{\circ} \mathrm{C}$, increasing $0.2{ }^{\circ} \mathrm{C}$ per cycle, ending at $95^{\circ} \mathrm{C}$ ). Experiments were performed with biological triplicates. Notemplate controls were run for every primer pair, and no-RT (reverse transcriptase) controls were run for every RNA sample. Transcript levels of $t t g$ genes were estimated by comparing their $\mathrm{Ct}$ (cycle threshold) values to the $\mathrm{Ct}$ value of the housekeeping gene rpoD (Wang and Nomura 2010). Final expression levels were averaged for each mutant strain and normalized to the expression level of the $P$. putida GS1 wild-type strain using the following formula:

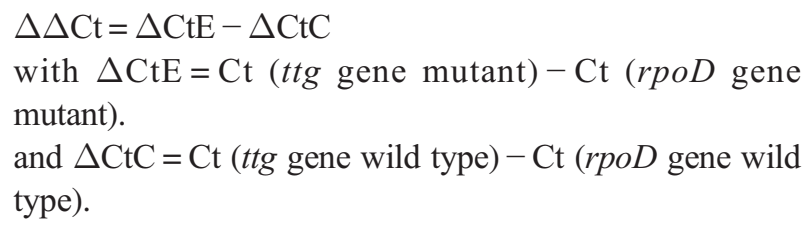

Gene expression fold change was calculated as follows:

Fold change $=2^{-\Delta \Delta \mathrm{Ct}}$.
For statistical analysis, Shapiro-Wilk normality test, followed by pairwise comparison using van der Waerden normal score test with Benjamini-Yakutiel $p$ value adjustment, was applied on $\Delta \mathrm{Ct}$ values.

\section{Efflux activity assay}

Efflux pump activity of $P$. putida wild type and mutants was determined via resazurin accumulation assay described by Vidal-Aroca et al. (2009). Ten milliliter LB medium in 100$\mathrm{ml}$ Erlenmeyer flasks was inoculated from overnight cultures to an $\mathrm{OD}_{600}$ of 0.1 and grown at $30^{\circ} \mathrm{C}$ and $180 \mathrm{rpm}$ to midexponential phase $\left(\mathrm{OD}_{600}\right.$ around 1$)$. Cells were harvested by centrifugation $(12,000 \times \mathrm{g}, 3 \mathrm{~min})$. The cell pellets were washed two times with $1 \times$ PBS buffer and resuspended in PBS $+0.4 \%$ glucose. Fluorescence signal was measured with an Infinite ${ }^{\circledR} 200$ PRO microtiter plate reader (Tecan). Experiments were performed with biological triplicates. The slope of the fluorescence increase was averaged for each strain over $50 \mathrm{~min}$ of the experiment and compared to the wild-type value. For statistical analysis, Shapiro-Wilk normality test, followed by pairwise comparison using van der Waerden normal score test with Benjamini-Yakutiel $p$ value adjustment, was applied on slope mean values of fluorescence measurements.

\section{Biotransformation experiments}

An approach modified from Mi et al. (2014) was used. Precultures of $P$. putida GS1 WT and mutant strains grown in TB medium were diluted with TB medium to an $\mathrm{OD}_{600}$ of 0.1 . Cultures were divided into $1.5 \mathrm{ml}$ aliquots in 48 -well Flowerplates ${ }^{\circledR}$ (m2p-labs GmbH, Baesweiler, Germany), and $35 \mathrm{mM}$ geraniol as biotransformation substrate was added directly after inoculation. Cells were incubated for $38 \mathrm{~h}$ at $30{ }^{\circ} \mathrm{C}$ in a microbioreactor system (BioLector ${ }^{\circledR}$ ) at $1000 \mathrm{rpm}$ covered with gas-permeable sealing foil. Biomass formation was monitored via scattered light signal intensity at $620 \mathrm{~nm}$. Geranic acid concentrations at different time points $(0,12,21$, and $38 \mathrm{~h})$ were determined by HPLC analysis. All strains were tested in triplicates, distributed randomly on the plate.

To P. putida culture samples of $150 \mu \mathrm{l}, 15 \mu \mathrm{l} 1 \mathrm{M} \mathrm{HCl}$ was added and analytes were extracted using $165 \mu$ l hexane containing $1 \mathrm{mM}$ thymol as an internal standard. Samples were centrifuged $(16,000 \times \mathrm{g}, 5 \mathrm{~min})$, and the organic phase was analyzed by HPLC, consisting of a diode array detector and a C18 column (Alltech Alltima, C18, $5 \mu \mathrm{m}, 250 \times 4.6 \mathrm{~mm}$; C18 Precolumn, Grace GmbH and Co. KG, Worms, Germany). Substances were separated isocratically using acetonitrile/acidified water (containing $0.05 \%(v / v) 3 \mathrm{M}$ phosphoric acid) in a ratio of 45:55 $(v / v)$ as mobile phase. After 
each run, the column was washed with 90:10 mixture of acetonitrile/acidified water.

For statistical analysis, Shapiro-Wilk normality test, followed by pairwise comparison using van der Waerden normal score test with Benjamini-Yakutiel $p$ value adjustment, was applied.

\section{Results}

\section{Tolerance of $P$. putida GS1 towards monoterpenoids}

For the development of microbial monoterpenoid production strains, a deep molecular understanding of the tolerance mechanisms for such compounds represents a prerequisite. As P. putida shows strong monoterpenoid tolerance (Inoue and Horikoshi 1991; Speelmans et al. 1998; Mi et al. 2014; Rau et al. 2016) and its organic solvent resistance mechanisms have been extensively studied (Isken and de Bont 1998; Ramos et al. 2015), we chose the P. putida strain GS1 (Speelmans et al. 1998) to explore its behavior after exposure to a number of different monoterpenoids (Fig. 1).

The effects of the different compounds on the growth of P. putida GS1 were investigated by comparing characteristics of the growth curves from microbioreactor cultivations under the influence of exogenously added chemicals. Cell density was monitored via scattered light signal and GFP fluorescence measurements. Experiments without addition and with different concentrations of monoterpenes and monoterpenoids had previously confirmed that growth curves obtained by scattered light signal measurements and fluorescence measurements are comparable for most of the substances tested (Online Resource Fig. S1-Fig. S4) and that GFP gene expression does not influence the growth of $P$. putida. Only in the case of geranic acid an interference of the substance with the scattered light signal could be observed and the GFP signal was necessary to monitor growth.

Analysis of the resulting data showed that the monoterpenes and monoterpenoids affect growth of $P$. putida GS1 differently (Fig. 2, Online Resource Fig. S2-Fig. S4). The bacterium could cope with the hydrocarbons (myrcene, $\alpha$ terpinene, $\gamma$-terpinene) up to the highest tested concentration of $200 \mathrm{mM}$ and the esterified monoterpenoids (geranyl acetate, geranyl formate, $\alpha$-terpinyl acetate) up to the highest tested concentration of $100 \mathrm{mM}$ without any apparent effect on its growth. The aldehyde citral, the ether 1,8-cineole, and the alcohols geraniol and linalool caused a slight prolongation of the lag phase when added in concentrations between 100 and $200 \mathrm{mM}$. However, if geraniol, linalool, or geranyl acetate were added, $P$. putida GS1 reached higher maximal GFP fluorescence intensities compared with cultures without monoterpenoid addition. Addition of $200 \mathrm{mM}$ geranic acid caused a reduction in growth rate and a slightly prolonged lag phase. The most pronounced growth inhibition was observed for the ketone verbenone and the alcohols $\alpha$-terpineol and terpinen-4-ol, which caused lag phase prolongations of more than $10 \mathrm{~h}$ if present in concentrations of 35,60 , and $80 \mathrm{mM}$, respectively.

Testing different concentrations of the same monoterpenoid revealed a positive correlation between compound concentration and severity of growth inhibition (Online Resource Fig. S1).

\section{Isolation and investigation of monoterpenoid-hypertolerant mutants}

In order to investigate the molecular mechanisms of monoterpenoid tolerance in P. putida GS1 and their specificities, a mutant library was created by transposon mutagenesis<smiles>C=CC(=C)CCC=C(C)C</smiles>

myrcene

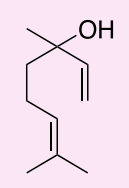

linalool

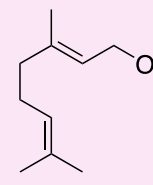

geraniol

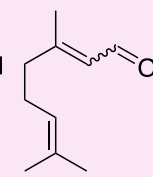

citral

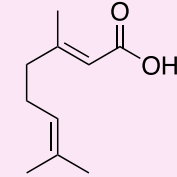

geranic acid

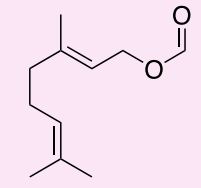

geranyl formate

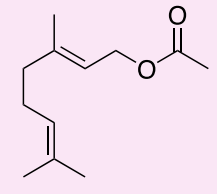

geranyl acetate

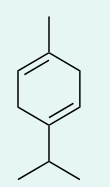

$\gamma$-terpinene

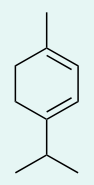

$\alpha$-terpinene

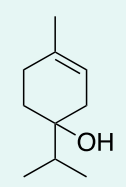

terpinen-4-ol

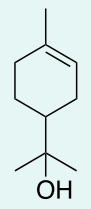

$\alpha$-terpineol

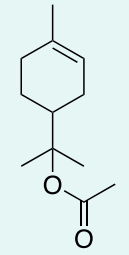

$\alpha$-terpinyl acetate
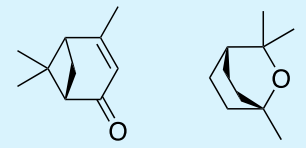

verbenone 1,8-cineole

Fig. 1 Chemical structures of monoterpenes and monoterpenoids used in this study. Red: linear, green: monocyclic, blue: bicyclic structures 


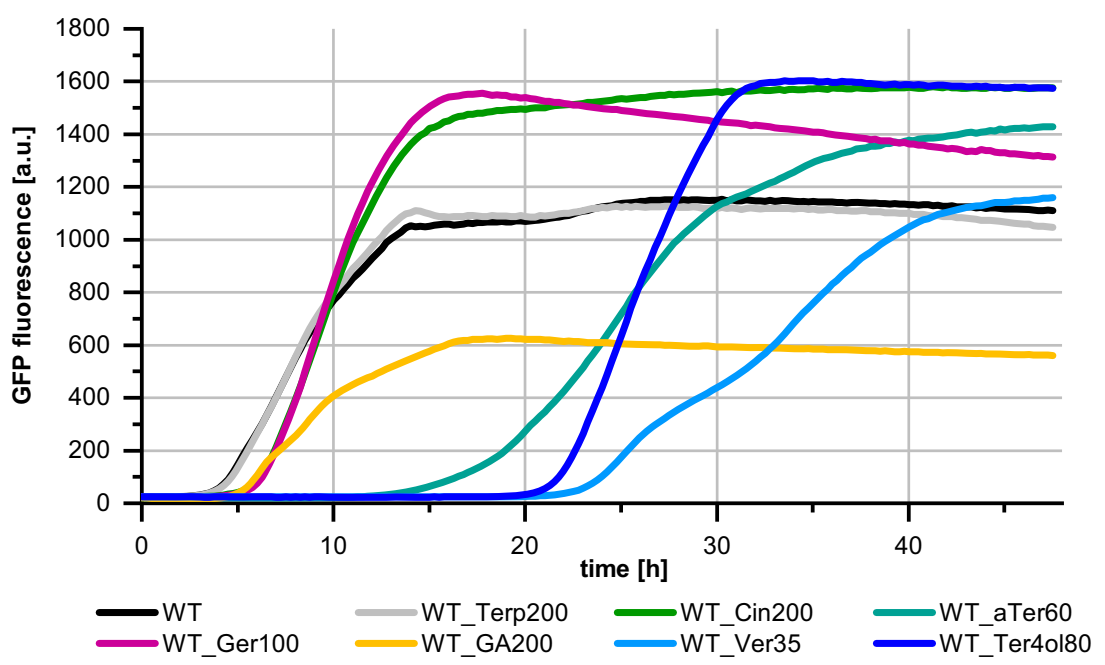

Fig. 2 Growth of P. putida GS1 (WT) + pMiS4-eGFP without and in the presence of different monoterpenes and monoterpenoids. Terp200: $\gamma$ terpinene $(200 \mathrm{mM})$, Cin200: 1,8-cineole $(200 \mathrm{mM})$, aTer60: $\alpha$ terpineol $(60 \mathrm{mM})$, Ger100: geraniol $(100 \mathrm{mM})$, GA200: geranic acid (200 mM), Ver35: verbenone (35 mM), Ter4ol80: terpinen-4-ol $(80 \mathrm{mM})$. Tolerance assays were conducted in a microbioreactor system

with a Himarl mariner transposon (Lampe et al. 1999; Klebensberger et al. 2007; Li et al. 2010). The mutant library was grown in the presence of one of the toxic compounds 1,8 cineole, geranic acid, geraniol, $\alpha$-terpineol, or verbenone, and monoterpenoid-hypertolerant mutants were selected. To ensure a large diversity at the starting point, also P. putida GS1 wild-type cells were added to the mutant selection process. After testing the phenotypes of several mutants, one representative with improved growth characteristics towards the specific selection monoterpenoid (shorter lag phase and/or increased growth rate) compared with the WT strain was chosen for further studies. The strains were named according to the monoterpenoid used as selective agent: 1,8-cineole-resistant (CR), geranic acid-resistant (GAR), geraniol-resistant (GR), $\alpha$-terpineol-resistant (TR), and verbenone-resistant (VR1) mutant.

Without the addition of monoterpenoids, the mutants showed similar growth curve characteristics as the wild-type strain (Online Resource Fig. S5). Monoterpenoid tolerance assays in microbioreactor cultivations with 1,8-cineole $(200 \mathrm{mM})$, geraniol $(100 \mathrm{mM}), \alpha$-terpineol $(60 \mathrm{mM})$, terpinen-4-ol $(80 \mathrm{mM})$, or verbenone $(35 \mathrm{mM})$ revealed improved tolerance of the mutant strains CR, GR, TR, and VR1 compared with the wild-type strain (Fig. 3a, Online Resource Fig. S6-Fig. S12). The most profound tolerance phenotypes for these compounds were obtained for the TR and the VR1 mutant. In contrary, when CR, GR, TR, and VR1 were exposed to $200 \mathrm{mM}$ geranic acid, their growth was impaired to a higher extent than that of the wild-type strain (Fig. 3b). The only exception was the GAR mutant, which showed an improved tolerance towards geranic acid compared with the wild-type strain (Fig. 3b). However, the GAR strain was much over $48 \mathrm{~h}$. Biomass formation was monitored every $10-15$ min via GFP fluorescence signal intensity (excitation filter $488 \mathrm{~nm}$; emission filter $520 \mathrm{~nm}$ ). The data points represent the mean values of three biological replicates. For variations between the replicates of each strain, see Online Resource Fig. S18

more sensitive towards all other monoterpenoids tested (Fig. 3a, Online Resource Fig. S6-Fig. S12).

To identify the genotypic characteristics causing the specific monoterpenoid-hypertolerant phenotypes of the mutants, either a splinkerette PCR approach was applied to identify transposon integration sites, or whole genome sequencing. The results are summarized in Fig. 4a, b, Table 1, and Online Resource Table S2. In the CR mutant, the transposon was localized in the $\operatorname{tg} R$ gene, the transcriptional regulator of the genes encoding the TtgABC efflux pump. The transposon in the GR mutant was found to be inserted in the $\operatorname{tg} T$ gene, the transcriptional regulator repressing transcription of the $\operatorname{ttg} D E F$ operon. Genome analysis of GAR, TR, and VR1 revealed no mariner transposon sequence but distinct other mutations. In the TR mutant, a 10-nucleotide deletion was identified in the region directly behind the transcription start of the $\operatorname{ttg} A B C$ operon. The deleted region includes the -35 region of the $\operatorname{tg} R$ promoter.

In order to verify the correlation between the identified Ttgrelated mutations in the $\mathrm{CR}$, GR, and TR mutant and improved monoterpenoid tolerance, $P$. putida GS1 strains were constructed which contain a deletion of either the $\operatorname{tg} R$ or the $\operatorname{tg} T$ gene or lack the 10 nucleotides in the region between the $\operatorname{tg} R$ and $\operatorname{tg} A$ open reading frames according to the respective mutation observed in the TR genome. Monoterpenoid tolerance assays conducted with the constructed deletion mutants $\Delta \operatorname{tg} R, \Delta \operatorname{tg} T$, and $\Delta 10 \mathrm{nt}_{\mathrm{tgABC}-5^{\prime} \mathrm{UTR}}$ and the original mutants $\mathrm{CR}$, GR, and TR showed comparable tolerance phenotypes (Online Resource Fig. S13-Fig. S15). When the CR and $\Delta \operatorname{ttg} R$ or the GR and $\Delta \operatorname{tg} T$ strains were complemented with a plasmid for expression of the $\operatorname{tg} R$ or the $\operatorname{tg} T$ gene, respectively, the mutant strains showed a similar sensitivity towards 
Fig. 3 Growth of $P$. putida GS1 WT and mutants + pMiS4-eGFP in the presence of a $35 \mathrm{mM}$ verbenone (Ver35) or b $200 \mathrm{mM}$ geranic acid (GA200). Tolerance assays were conducted in a microbioreactor system over $48 \mathrm{~h}$. Biomass formation was monitored every $10-15$ min via GFP fluorescence signal intensity (excitation filter $488 \mathrm{~nm}$; emission filter $520 \mathrm{~nm}$ ). The data points represent the mean values of three biological replicas. For variations between the replicas of each strain, see Online Resource Fig. S24 and Fig. S28
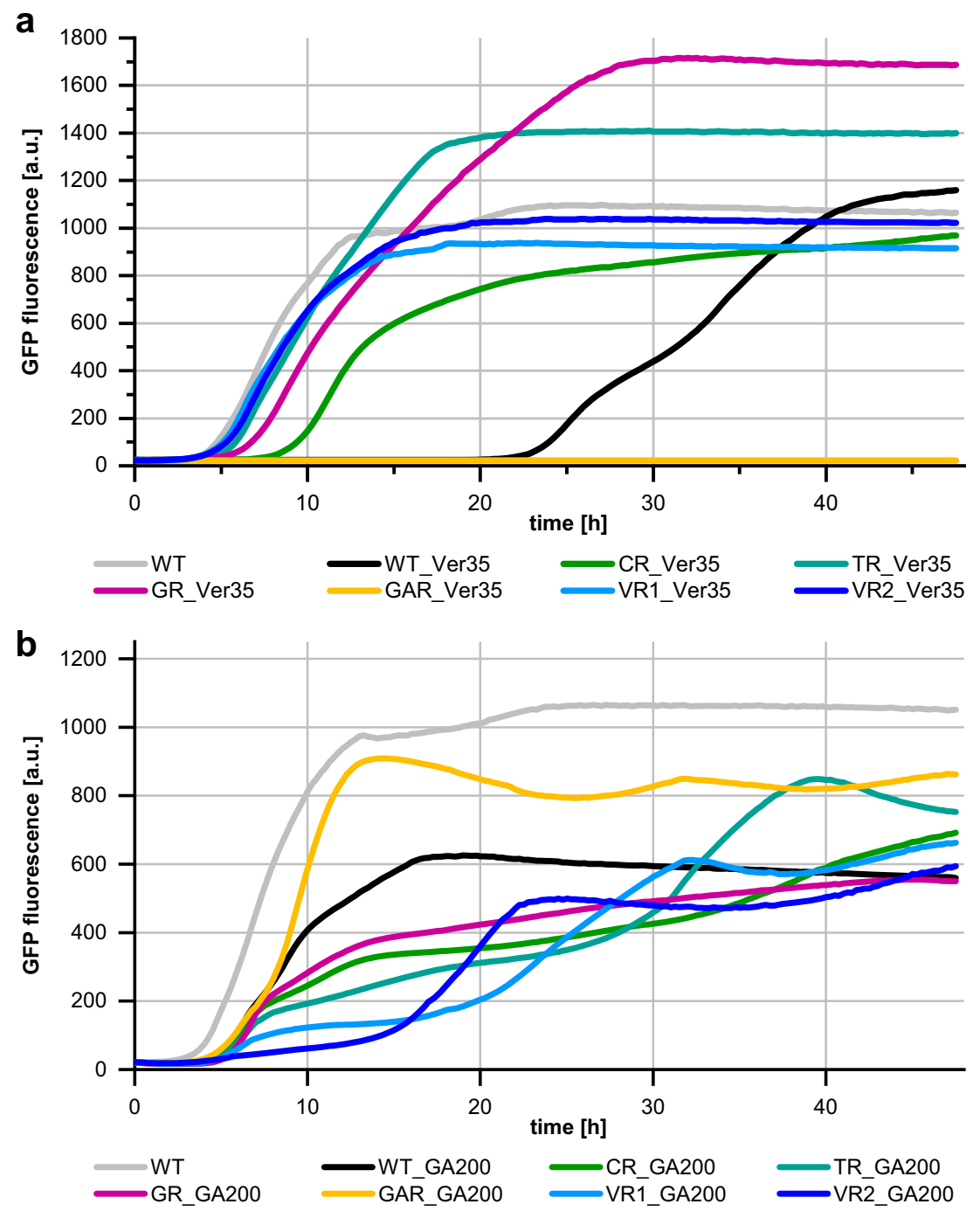

the monoterpenoids as the wild-type strain. These results confirm that deletion of both the $\operatorname{tg} R$ and the $\operatorname{tg} T$ gene as well as the deletion of $10 \mathrm{bp}$ in the region between the $\operatorname{tg} R$ and $\operatorname{tg} A$ open reading frames are causal for the observed monoterpenoid-hypertolerant phenotypes of CR, GR, and TR.

Analysis of the genome sequence data obtained for the GAR mutant revealed a deletion of 41 nucleotides in the $\operatorname{ttg} A$ gene, coding for a subunit of the TtgABC efflux system. The deletion results in a stop codon after nucleotide 207 of the open reading frame.

In the genome of VR1, a variety of different mutations were identified (Online Resource Table S2). Because none of the identified mutations could be directly linked to an increased monoterpenoid tolerance, a second mutant selected in the presence of verbenone (VR2) was investigated. VR2 showed similar tolerance phenotypes in the tolerance assays compared with VR1 (Fig. 3, Online Resource Fig. S6-Fig. S12) and again over 30 different mutations were identified in its genome (Online Resource Table S2). In both strains, a mutation was present in a gene encoding a DNA repair protein (VR1: $m u t S$, VR2: $m u t L$ ). In addition, the genomes of both strains contained a mutation in one of the nuo genes (VR1: $n u o B$, VR2: $n u \circ G$ ), encoding subunits of NADH-quinone oxidoreductase/NADH dehydrogenase, which is part of the respiratory chain.

As the analysis of VR1 and VR2 genome sequences did not reveal indications for efflux pump alterations, we aimed to test a putative detoxification of verbenone by degradation or conversion by these mutants. However, this hypothesis could be disproven by GC-MS analyses. No conversion products were detectable, and verbenone concentration decreased in the VR cultures over time with the same rate as with WT cells and in the medium control without cells (Online Resource Fig. S16).

Quantitative PCR analysis of mRNA levels of $t \mathrm{tg}$ genes $\operatorname{ttg} R, \operatorname{ttg} A, \operatorname{ttg} B, \operatorname{ttg} T$, and $\operatorname{tg} E$ showed reduced expression of $\mathrm{TtgR}$ and increased production of $\mathrm{Ttg} \mathrm{ABC}$ efflux system in the CR mutant (Fig. 4c). In the TR mutant, transcription of the $\operatorname{ttg} A B C$ efflux pump genes were also significantly enhanced. 
a
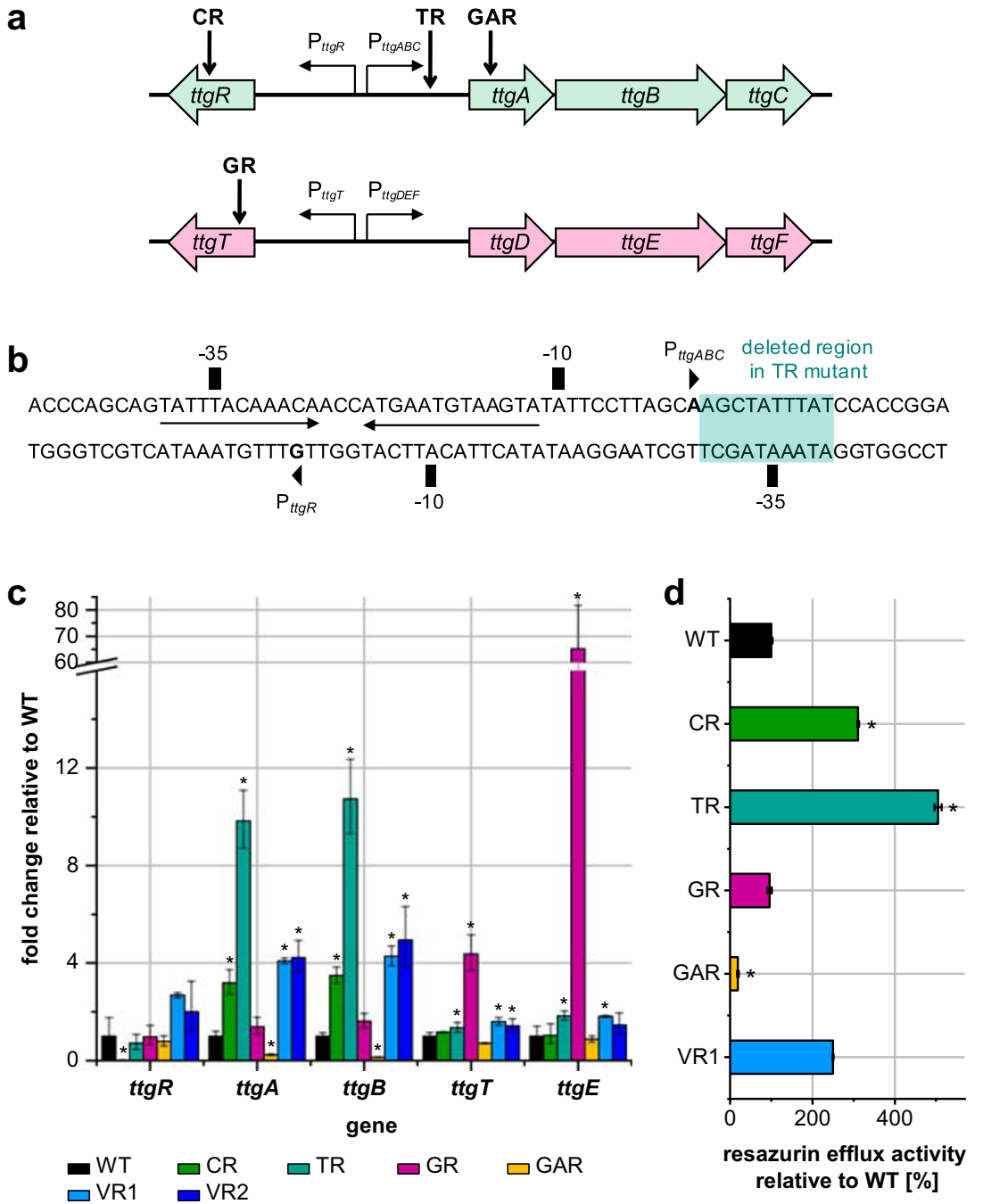

Fig. 4 Further characterization of mutant strains (CR, TR, GR, GAR, VR1, and VR2). a Localization of identified mutations in different mutant strains. b Nucleotide sequence of the $\operatorname{tg} A B C$ - $\operatorname{tg} R$ intergenic region. Deleted region in TR mutant is highlighted in green. The putative TtgR palindromic recognition site is indicated by the arrows; $\operatorname{ttg} A B C$ and $\operatorname{tg} R+1$ (arrowheads), -10 , and -35 points are marked according to Terán et al. (2003). c Relative expression levels of $t$ tg genes in mutants compared with $P$. putida GS1 wild type $\left(2^{-\Delta \Delta \mathrm{Ct}}\right)$. d Resazurin efflux pump activity of $P$. putida GS1 mutant strains relative to wild type. Slope mean values of fluorescence increase over time of mutant strains

The opposite was the case with the GAR mutant, which showed a decrease of the TtgABC efflux system mRNA levels. In the GR mutant, the expression of the TtgDEF efflux system was increased. VR1 and VR2 also showed an enhanced mRNA quantity of both efflux pump systems compared with the GS1 wild type.

To measure the efflux activity of the different strains, an efflux pump activity assay was performed according to a protocol by Vidal-Aroca and colleagues (2009). The experiments revealed a reduced resazurin efflux activity for the GAR mutant compared with the wild-type strain (Fig. 4d). While no difference in resazurin efflux activity could be measured normalized to wild type are given. Cells were grown in LB medium until mid-exponential phase and resuspended in PBS buffer with resazurin. Efflux activity was monitored by measuring the fluorescence intensity of resazurin reduction product resorufin (excitation filter $530 \mathrm{~nm}$; emission filter $590 \mathrm{~nm}$ ). While a slow increase in fluorescence indicates high efflux activity, a high slope shows low efflux activity. In $\mathbf{c}$ und $\mathbf{d}$, results represent the mean values and standard deviations of three biological replicates. The asterisks indicate a significant difference for the mutant strains compared with wild-type GS1 according to van der Waerden normal score test with Benjamini-Yakutiel $p$ value adjustment $(p<0.05)$

between the GR mutant and the wild type, an increased efflux was observed for the CR, TR, and VR1 mutant in the experiments.

\section{Geranic acid biotransformation performance of monoterpenoid-hypertolerant strains}

For efficient and robust microbial monoterpenoid de novo production or biotransformation processes, both tolerance of the cells towards educts and products, and productivity should be as high as possible, whereby interactions between these parameters are possible. In order to investigate if the altered 
Table 1 Mutant strains, selection substances, and identified mutations presumably causing the altered monoterpenoid tolerance phenotypes

\begin{tabular}{|c|c|c|}
\hline Mutant & $\begin{array}{l}\text { Selection } \\
\text { substance }\end{array}$ & Mutation responsible for or involved in evolution of hypertolerance phenotype \\
\hline $\mathrm{CR}$ & 1,8-Cineole & $\begin{array}{l}\text { Transposon insertion in } \operatorname{ttg} R \text { gene ( } 487 \text { nucleotides downstream of start codon) } \\
\operatorname{ttg} R \rightarrow \text { transcriptional regulator of } \operatorname{tg} A B C \text { operon }\end{array}$ \\
\hline TR & $\alpha$-Terpineol & $\begin{array}{l}\text { Deletion of } 10 \text { nucleotides in } 5 \text { '-UTR of } \operatorname{ttg} A B C \text { mRNA (directly after } \mathrm{P}_{t \operatorname{tg} A B C}+1 \text { ) } \\
\text { and }-35 \text { region of } \mathrm{P}_{\operatorname{tg} R}\end{array}$ \\
\hline GR & Geraniol & $\begin{array}{l}\text { Transposon insertion in } \operatorname{tg} T \text { gene ( } 40 \text { nucleotides downstream of start codon) } \\
\operatorname{ttg} T \rightarrow \text { transcriptional regulator of } \operatorname{tg} D E F \text { operon }\end{array}$ \\
\hline GAR & Geranic acid & $\begin{array}{l}\text { Deletion of } 41 \text { nucleotides in } \operatorname{tg} A \text { gene ( } 109 \text { nucleotides downstream of start } \\
\text { codon) } \\
\operatorname{ttg} A \rightarrow \text { subunit of TtgABC efflux system }\end{array}$ \\
\hline VR1 & Verbenone & $\begin{array}{l}\text { - } 33 \text { different mutations (16-nucleotide deletion, } 32 \text { single nucleotide exchanges) } \\
\text { - DNA repair protein (mutS) } \\
\text { - Subunit of respiratory chain protein (nиоB) }\end{array}$ \\
\hline VR2 & Verbenone & $\begin{array}{l}\text { - } 32 \text { different mutations (1 nucleotide deletion, } 1 \text { nucleotide insertion, } 30 \text { single } \\
\text { nucleotide exchanges) } \\
\text { - DNA repair protein }(m u t L) \\
\text { - Subunit of respiratory chain protein }(\text { nuoG) }\end{array}$ \\
\hline
\end{tabular}

monoterpenoid tolerance properties of the mutant strains influence their bioconversion abilities, they were employed for the conversion of geraniol into geranic acid. P. putida GS1 has been demonstrated to carry out this biotransformation (Mi et al. 2014). Geraniol (35 mM) was added directly after inoculation of the cultures in the microbioreactor system, and geranic acid concentration was determined at different time points within $38 \mathrm{~h}$ (Fig. 5).

In the wild-type culture, a product concentration of $15 \mathrm{mM}$ was reached after $12 \mathrm{~h}$, which increased up to $16 \mathrm{mM}$ until $38 \mathrm{~h}$. Using the TR strain, a geranic acid concentration of $9.5 \mathrm{mM}$ was observed after $38 \mathrm{~h}$. The mutants CR and GR produced geranic acid levels in the range of the wild-type value. Only with the geranic acid mutant GAR, the used geraniol was nearly completely oxidized to $32 \mathrm{mM}$ geranic acid after $38 \mathrm{~h}$. However, the whole conversion took place in the last $14 \mathrm{~h}$ of the experiment. This observation was accompanied by the growth curve of GAR. While the wild-type strain and the other mutants started to grow about $5 \mathrm{~h}$ after inoculation, cell density of the GAR mutant started to increase after $20 \mathrm{~h}$.

\section{Discussion}

It is long known that some essential oils and their monoterpenoid compounds exhibit antimicrobial properties. However, the specific bacterial mechanisms causing the natural tolerance of, e.g., Pseudomonas putida strains towards specific monoterpenoids have hardly been explored. A deeper understanding of the underlying factors and the specificities of the mechanisms is crucial for the development of highly efficient and robust microorganisms producing monoterpenoids de novo or via biotransformation.

In the conducted experiments, the different monoterpenes and monoterpenoids affected the growth behavior of $P$. putida GS1 wild type very differently. None of the tested hydrocarbons and esterified monoterpenoids showed an inhibitory effect on cell growth in the concentrations tested. This indicates that no inhibition of cell functions takes place or that the cells can protect themselves against the substances without affecting growth. Addition of the alcohols, aldehyde, ether, ketone, and acid caused a prolongation of the lag phase, but to different extents. These results are in accordance with the general assumption that the toxicity of a particular substance correlates with its hydrophobicity. The hydrophobicity determines to what extent the compound accumulates in the cytoplasmic membrane. A measure of the hydrophobicity is the logarithm of the octanol-water partition coefficient $\left(\log P_{\text {ow }}\right)$ of the respective substance, with values between 1 and 4.5. The lower the $\log P_{\text {ow }}$ value, the more toxic the substance is (Inoue and Horikoshi 1989; Sikkema et al. 1994; Ramos et al. 2002; Kabelitz et al. 2003; Dunlop 2011). According to the SciFinder database, the $\log P_{\text {ow }}$ value increases as follows: verbenone $<$ terpinen-4-ol $<\alpha$-terpineol $<$ linalool $=1,8$-cineole $<$ geraniol $<$ geranic acid $<$ citral $<$ geranyl formate $<$ $\alpha$-terpinyl acetate $<$ geranyl acetate $<\gamma$-terpinene $<$ $\alpha$-terpinene.

Apart from the chemical and physical properties that determine the toxicity of the monoterpenes and monoterpenoids, the observed effects also depend on how effectively $P$. putida GS1 can defend itself against the various substances with its inherent mechanisms. While in the genome of $P$. putida DOT$\mathrm{T} 1 \mathrm{E}$ the genes of three different $\mathrm{Ttg}$ efflux systems, TtgABC, 
Fig. 5 Geranic acid production (a) and growth (b) of P. putida GS1 WT and mutants (CR, TR, GR, GAR) in a geraniol to geranic acid biotransformation. The experiment was conducted in a microbioreactor system over $38 \mathrm{~h}$. To determine geranic acid concentration, samples were taken at time points $t=0,12,21$, and $38 \mathrm{~h}$ and analyzed via HPLC. The data points represent the mean values and standard deviations of three biological replicas. The asterisks indicate a significant difference for the mutant strains as compared with wild-type GS1 according to van der Waerden normal score test with Benjamini-Yakutiel $p$ value adjustment $(p<0.05)$. Biomass formation was monitored every $10-15$ min via scattered light signal intensity (absorbance at $620 \mathrm{~nm}$ ). The data points represent the mean values of three biological replicas. For variations in growth between the replicas of each strain, see Online Resource Fig. S29
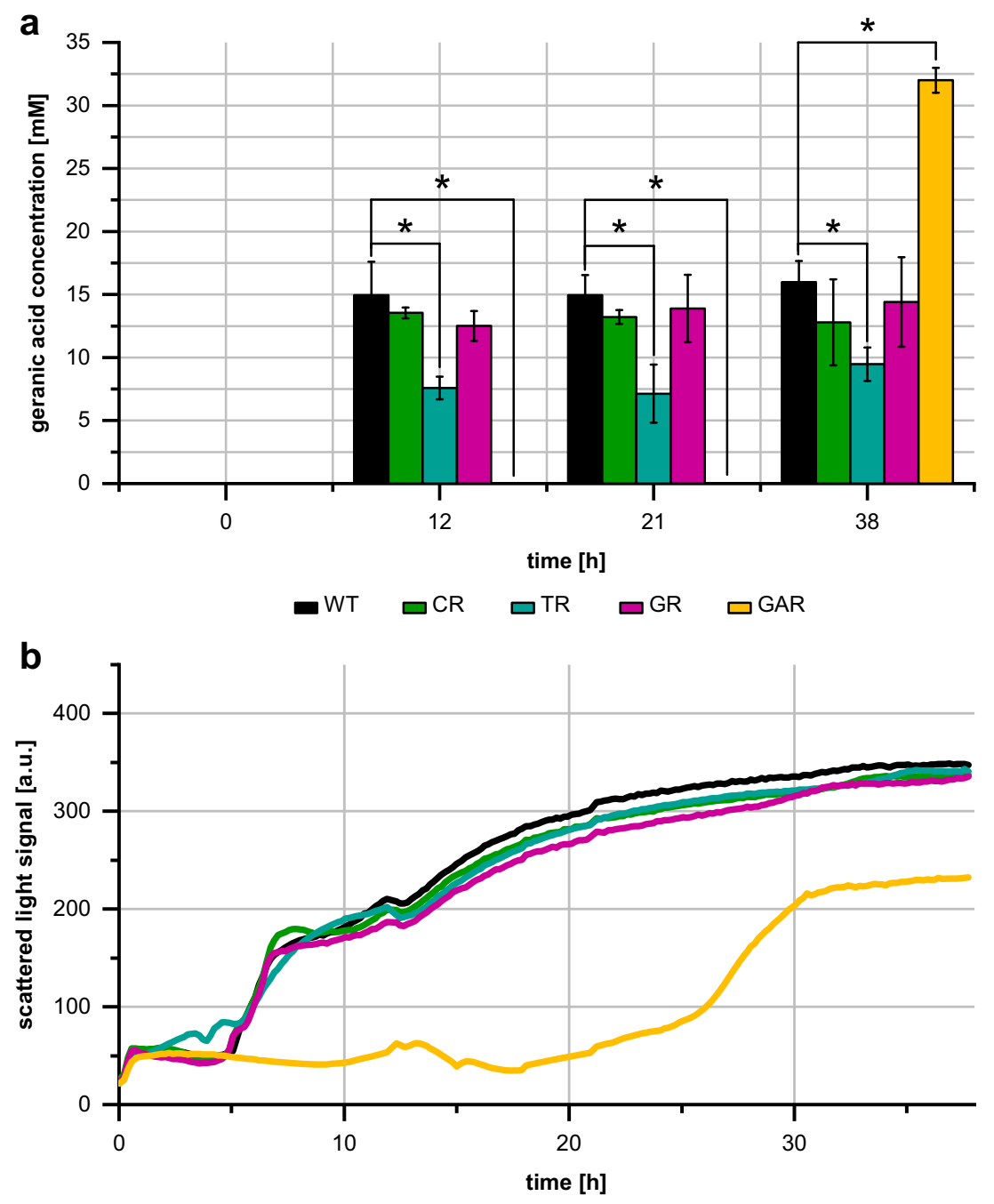

TtgDEF and TtgGHI, were found (Segura et al. 2003), the frequently used KT2440 strain contains only the TtgABC system (Nelson et al. 2002). Genome sequencing of the GS1 strain revealed two Ttg efflux systems, TtgABC and TtgDEF, which are very similar to the systems in KT2440 and DOT-T1E (Online Resource Table S3). Some of these systems, such as the TtgABC efflux pump, mediate an intrinsic basal solvent tolerance (Ramos et al. 1998; Rojas et al. 2001). Other mechanisms, such as the expression of the $\operatorname{tg} D E F$ operon or an increased TtgABC production, first have to be activated (Mosqueda and Ramos 2000; Rojas et al. 2001; Ramos et al. 2015). This can prolong the lag phase in the presence of toxic compounds, because the cells can only protect themselves effectively against the substances after the genes have been expressed. However, the fact that in the presence of verbenone, $\alpha$-terpineol and terpinene-4-ol growth is delayed for more than $10 \mathrm{~h}$, is probably not only due to the circumstance that transcription of tolerance mechanisms, such as efflux pumps, first has to be induced. Even with activated efflux pumps, the concentration of the substances in the medium must decrease below a certain value before cell growth is no longer inhibited. Experiments with verbenone showed that the monoterpenoid concentration in the cultures decreases over time (Online Resource Fig. S16) due to evaporation. The concentration reached after about $15 \mathrm{~h}$ was ca. $15 \mathrm{mM}$, which did not cause strong inhibitory effects in previous experiments (Online Resource Fig. S1).

In addition to a prolonged lag phase, the presence of $\alpha$-terpineol, verbenone, and geranic acid impaired growth rate and in the case of geranic acid growth yield. These effects can be explained by an alteration of cellular processes and metabolic fluxes in the cells, e.g., due to increased membrane permeability or the inhibition of certain proteins (Sikkema et al. 1994). Furthermore, the high energy demand of efflux pump activity can cause a reduced growth yield (Ramos et al. 1997; Isken et al. 1999).

The positive effect of some compounds on the maximal biomass yield of $P$. putida GS1 might be explained by a 
metabolization of the monoterpenoids. As described previously, P. putida GS1 is not able to utilize geraniol or geranic acid as sole carbon source (Cantwell et al. 1978; Mi et al. 2014), but can oxidize geraniol into geranic acid, thereby forming $\mathrm{NADH}$ and $\mathrm{FADH}_{2}$ (Mi et al. 2014) and providing the cells with an additional energy source.

To further elucidate the monoterpenoid tolerance mechanisms in P. putida GS1, we isolated and characterized monoterpenoid-hypertolerant mutants. Tolerance assays with selected strains showed different extents of tolerance improvement and different specificities. Genome sequencing, gene expression quantification of $t \mathrm{tg}$ genes, and efflux activity assays provided further insight into differences between the mutant strains on the cellular level.

In the CR and GR strain, transposon insertion in the $t$ tgR or $\operatorname{ttg} T$ repressor gene, respectively, resulted in a constitutive and increased expression of the corresponding efflux pump proteins TtgABC or TtgDEF (Duque et al. 2001; Terán et al. 2007). Constitutive efflux pump expression can improve solvent tolerance (Fukumori et al. 1998; Duque et al. 2001; Rau et al. 2016) and usually results in a clear reduction of the increased lag phase duration caused by the toxic compound.

The 10-nucleotide deletion in the TR mutant covers the region of the $\operatorname{tg} A B C-5^{\prime}$-UTR directly after the transcription start as well as the -35 region of the $\operatorname{ttg} R$ promoter (Terán et al. 2003). The hypertolerance phenotype can be a result of increased $\operatorname{tg} A B C$ mRNA stability or translation rate. Quantitative PCR experiments showed enhanced transcript levels of the $\operatorname{tg} A B C$ operon in the TR mutant, which fits to increased efflux activity compared with the wild type. This results in improved solvent tolerance (Fukumori et al. 1998; Duque et al. 2001), as shown in the growth experiments with different monoterpenoids.

In the GAR mutant, the deletion in the ttgA gene results in a loss of the TtgABC efflux system accompanied by a reduced resazurin efflux activity. The strain showed an increased sensitivity towards the tested monoterpenoid alcohols, 1,8-cineole, and verbenone, indicating that a functional TtgABC efflux system is not only essential for the tolerance towards toluene and different antibiotics (Ramos et al. 1998; Rojas et al. 2001; Martínez-García and de Lorenzo 2011), but also for monoterpenoid resilience of P. putida GS1. The relation between an active efflux and improved monoterpenoid tolerance is in accordance with previous findings. Papadopoulos and colleagues reported that in Pseudomonas aeruginosa, the MexAB-OprM efflux system plays a decisive role for the strain's tolerance towards monoterpenoids such as terpinen-4-ol, 1,8-cineole, and $\alpha$ terpineol and that the absence of a pump subunit or the entire pump leads to a higher sensitivity towards different monoterpenoids (Papadopoulos et al. 2008). Also for E. coli (Shah et al. 2013) and eukaryotic systems (Wang et al. 2013), a causal connection between the presence of efflux pumps and tolerance to monoterpenes and monoterpenoids has been described. However, the correlation between efflux pump expression and monoterpenoid tolerance does not explain the increased tolerance of the GAR strain towards geranic acid, because in this case, loss of an efflux pump component increased the tolerance. A possible explanation is based on the presumption that the geranic acid import rate might be much higher compared with those of the other compounds. If such a continuous uptake is accompanied by a concomitant energy-demanding efflux (Ramos et al. 2002), a futile cycle would have been created. This hypothesis would also explain the clearly reduced growth rate and yield of the wild-type strain in the presence of geranic acid, caused by an energy-consuming futile cycle. The loss of TtgABC activity in the GAR mutant would thus interrupt the cycle and allow a higher growth rate again.

Analysis of the VR mutant genomes revealed more than 30 mutations each, but none of them was located in an efflux pump operon. Nevertheless, further experiments showed increased transcription of TtgABC and TtgDEF efflux pump systems concomitant with an enhanced resazurin efflux activity compared with the wild type. Which mutations lead to an increased expression of the efflux pump genes is unclear. However, the high number of mutations in both strains can be explained by mutations in $m u t S$ or $m u t L$, respectively, which are known to cause high mutation rates (Acharya et al. 2003; Brandt 2006). The fact that both independent strains represent mutator strains strongly indicates that the selection procedure with verbenone required a multigenic trait to bring up these highly tolerant strains. A comparison of the additional genome changes revealed that both strains have a point mutation in a nuo gene (VR1: nuоB, VR2: nuоG). NuоB and $n u \circ G$ encode subunits of NADH-ubiquinone oxidoreductase, which is part of the respiratory chain (Weidner et al. 1993; Camacho Carvajal et al. 2002). NuoB and nuoG were already found to be upregulated in P. putida S12 cells during toluene stress (Wijte et al. 2011). The nuo gene mutations in VR1 and VR2 could possibly lead to an increased catabolism to provide more ATP for monoterpenoid export or other tolerance mechanisms.

To test the applicability of such hypertolerant strains in biotechnological processes, geraniol to geranic acid biotransformation experiments were conducted. After $38 \mathrm{~h}$, a geranic acid concentration of around $16 \mathrm{mM}$ could be achieved with the wild-type strain, which corresponds to a product yield of $45 \%$ and is in accordance with previous studies (Mi et al. 2014). The experiments with the mutants showed that the different tolerance levels of the mutants, caused by differences in efflux activity, had an impact on the conversion of geraniol into geranic acid. The two extremes were the mutants TR and GAR. For the TR mutant, characterized by a high monoterpenoid tolerance and high level of resazurin efflux activity, geraniol conversion ability was significantly 
impaired. In contrast to this, an almost quantitative conversion of geraniol could be achieved with the GAR mutant (product yield $91 \%$ ). Our explanation for biotransformation performance reduction of the TR strain is an enhanced export of the biotransformation educt geraniol caused by $\operatorname{tg} A B C$ overexpression. The GAR mutant lacks this efflux pump and therefore presumably has no or strongly reduced geraniol export activity. This can lead to a strong improvement of the reaction yield, since the educt geraniol is available in the cells for bioconversion. The extraordinarily long lag phase, which was caused by the strong reduction or lack of geraniol efflux activity, can be overcome by separation of growth and production phase in a respective process.

In conclusion, our study demonstrates the highly different toxicity levels of certain monoterpenes and monoterpenoids and reveals the Ttg efflux pumps of P. putida GS1 to be mainly responsible for tolerance towards many of the tested compounds. The application example furthermore clearly demonstrates that a fine-tuned tailoring of transport and tolerance properties is essential for the design of efficient and robust biotechnological processes.

Acknowledgments We thank the Jenal group (Uni Basel) for providing us with the pALMAR-3 plasmid.

Author contribution F.M.S., J.M., H.S., J.S., and M.B. designed the research. F.M.S., K.E.H., J.M., F.K., and A.M. performed the experiments. F.M.S., K.E.H., J.M., F.K., and M.B. analyzed the data. F.M.S. and M.B. wrote the manuscript with input from all authors.

Funding information Open Access funding provided by Projekt DEAL. This research was supported by funds of the Federal Ministry of Food and Agriculture (BMEL) based on a decision of the Parliament of the Federal Republic of Germany via the Fachagentur Nachwachsende Rohstoffe e.V. (FNR, FKZ 22030615) under ERA-NET, funded from the European Union's Seventh Research Framework Program (ERA IB-2, 6th call, project BioProMo), and by the LOEWE project AROMAplus of the State of Hesse (Germany).

\section{Compliance with ethical standards}

Conflict of interest The authors declare that they have no conflict of interest.

Ethical approval This article does not contain any studies with human participants or animals performed by any of the authors.

Open Access This article is licensed under a Creative Commons Attribution 4.0 International License, which permits use, sharing, adaptation, distribution and reproduction in any medium or format, as long as you give appropriate credit to the original author(s) and the source, provide a link to the Creative Commons licence, and indicate if changes were made. The images or other third party material in this article are included in the article's Creative Commons licence, unless indicated otherwise in a credit line to the material. If material is not included in the article's Creative Commons licence and your intended use is not permitted by statutory regulation or exceeds the permitted use, you will need to obtain permission directly from the copyright holder. To view a copy of this licence, visit http://creativecommons.org/licenses/by/4.0/.

\section{References}

Acharya S, Foster PL, Brooks P, Fishel R (2003) The coordinated functions of the E. coli MutS and MutL proteins in mismatch repair. Mol Cell 12:233-246. https://doi.org/10.1016/S1097-2765(03)00219-3

Andrews RE, Parks LW, Spence KD (1980) Some effects of Douglas fir terpenes on certain microorganisms. Appl Environ Microbiol 40: 301-304

Berger RG (ed) (2007) Flavours and Fragrances. Springer-Verlag, Berlin, Heidelberg

Brandt U (2006) Energy converting NADH: quinone oxidoreductase (complex I). Annu Rev Biochem 75:69-92. https://doi.org/10. 1146/annurev.biochem.75.103004.142539

Breitmaier E (2005) Terpene, 2. Auflage. WILEY-VCH Verlag GmbH \& Co. KGaA, Weinheim. https://oi.org/10.1002/9783527623693

Camacho Carvajal MM, Wijfjes AHM, Mulders IHM, Lugtenberg BJJ, Bloemberg GV (2002) Characterization of NADH dehydrogenases of Pseudomonas fluorescens WCS365 and their role in competitive root colonization. Mol Plant-Microbe Interact 15:662-671. https:// doi.org/10.1094/MPMI.2002.15.7.662

Cantwell SG, Lau EP, Watt DS, Fall RR (1978) Biodegradation of acyclic isoprenoids by Pseudomonas species. J Bacteriol 135:324-333

Chen Y, Zhou YJ, Siewers V, Nielsen J (2015) Enabling technologies to advance microbial isoprenoid production. Adv Biochem Eng Biotechnol 148:143-160. https://doi.org/10.1007/10_2014_284

Choi K-H, Kumar A, Schweizer HP (2006) A 10-min method for preparation of highly electrocompetent Pseudomonas aeruginosa cells: application for DNA fragment transfer between chromosomes and plasmid transformation. J Microbiol Methods 64:391-397. https:// doi.org/10.1016/j.mimet.2005.06.001

Cornelissen S, Julsing MK, Volmer J, Riechert O, Schmid A, Bühler B (2013) Whole-cell-based CYP153A6-catalyzed (S)-limonene hydroxylation efficiency depends on host background and profits from monoterpene uptake via AlkL. Biotechnol Bioeng 110:1282-1292. https://doi.org/10.1002/bit.24801

Cornelissen S, Liu S, Deshmukh AT, Schmid A, Bühler B (2011) Cell physiology rather than enzyme kinetics can determine the efficiency of cytochrome P450-catalyzed C-H-oxyfunctionalization. J Ind Microbiol Biotechnol 38:1359-1370. https://doi.org/10.1007/ s10295-010-0919-y

Devon RS, Porteous DJ, Brookes AJ (1995) Splinkerettes-improved vectorettes for greater efficiency in PCR walking. Nucleic Acids Res 23:1644-1645. https://doi.org/10.1093/nar/23.9.1644

Dunlop MJ (2011) Engineering microbes for tolerance to next-generation biofuels. Biotechnol Biofuels 4:32. https://doi.org/10.1186/17546834-4-32

Dunlop MJ, Dossani ZY, Szmidt HL, Chu HC, Lee TS, Keasling JD, Hadi MZ, Mukhopadhyay A (2011) Engineering microbial biofuel tolerance and export using efflux pumps. Mol Syst Biol 7:487-487. https://doi.org/10.1038/msb.2011.21

Duque E, Segura A, Mosqueda G, Ramos JL (2001) Global and cognate regulators control the expression of the organic solvent efflux pumps TtgABC and TtgDEF of Pseudomonas putida. Mol Microbiol 39: 1100-1106. https://doi.org/10.1046/j.1365-2958.2001.02310.x

Franden MA, Jayakody LN, Li WJ, Wagner NJ, Cleveland NS, Michener WE, Hauer B, Blank LM, Wierckx N, Klebensberger J, Beckham GT (2018) Engineering Pseudomonas putida KT2440 for efficient ethylene glycol utilization. Metab Eng 48:197-207. https://doi.org/ 10.1016/j.ymben.2018.06.003

Fukumori F, Hirayama H, Takami H, Inoue A, Horikoshi K (1998) Isolation and transposon mutagenesis of a Pseudomonas putida KT2442 toluene-resistant variant: involvement of an efflux system in solvent resistance. Extremophiles 2:395-400

Gibson DG, Young L, Chuang R-Y, Venter JC, Hutchison CA, Smith HO (2009) Enzymatic assembly of DNA molecules up to several 
hundred kilobases. Nat Methods 6:343-345. https://doi.org/10. 1038/nmeth. 1318

Gotoh N, Tsujimoto H, Poole K, Yamagishi JI, Nishino T (1995) The outer membrane protein OprM of Pseudomonas aeruginosa is encoded by oprK of the mexA-mexB-oprK multidrug resistance operon. Antimicrob Agents Chemother 39:2567-2569. https://doi.org/ 10.1128/AAC.39.11.2567

Habermehl G, Hammann PE, Krebs HC, Ternes W (2008) Naturstoffchemie, 3. Springer, Berlin Heidelberg, Berlin, Heidelberg

Heipieper HJ, Meinhardt F, Segura A (2003) The cis-trans isomerase of unsaturated fatty acids in Pseudomonas and Vibrio: biochemistry, molecular biology and physiological function of a unique stress adaptive mechanism. FEMS Microbiol Lett 229:1-7. https://doi. org/10.1016/S0378-1097(03)00792-4

Inoue A, Horikoshi K (1991) Estimation of solvent-tolerance of bacteria by the solvent parameter log P. J Ferment Bioeng 71:194-196. https://doi.org/10.1016/0922-338X(91)90109-T

Inoue A, Horikoshi K (1989) A Pseudomonas thrives in high concentrations of toluene. Nature 338:264-266. https://doi.org/10.1038/ $338264 \mathrm{a} 0$

Inoue H, Nojima H, Okayama H (1990) High efficiency transformation of Escherichia coli with plasmids. Gene 96:23-28. https://doi.org/10. 1016/0378-1119(90)90336-p

Isken S, de Bont JA (1998) Bacteria tolerant to organic solvents. Extremophiles 2:229-238. https://doi.org/10.1007/s007920050065

Isken S, de Bont JA (1996) Active efflux of toluene in a solvent-resistant bacterium. J Bacteriol 178:6056-6058. https://doi.org/10.1128/jb. 178.20.6056-6058.1996

Isken S, Derks A, Wolffs PF, de Bont JA (1999) Effect of organic solvents on the yield of solvent-tolerant Pseudomonas putida S12. Appl Environ Microbiol 65:2631-2635

Kabelitz N, Santos PM, Heipieper HJ (2003) Effect of aliphatic alcohols on growth and degree of saturation of membrane lipids in Acinetobacter calcoaceticus. FEMS Microbiol Lett 220:223-227. https://doi.org/10.1016/S0378-1097(03)00103-4

Kieboom J, Dennis JJ, de Bont JA, Zylstra GJ (1998) Identification and molecular characterization of an efflux pump involved in Pseudomonas putida S12 solvent tolerance. J Biol Chem 273:8591. https://doi.org/10.1074/jbc.273.1.85

King EO, Ward MK, Raney DE (1954) Two simple media for the demonstration of pyocyanin and fluorescin. J Lab Clin Med 44:301-307

Klebensberger J, Lautenschlager K, Bressler D, Wingender J, Philipp B (2007) Detergent-induced cell aggregation in subpopulations of Pseudomonas aeruginosa as a preadaptive survival strategy. Environ Microbiol 9:2247-2259. https://doi.org/10.1111/j.14622920.2007.01339.x

Krell T, Terán W, Mayorga OL, Rivas G, Jiménez M, Daniels C, MolinaHenares A-J, Martínez-Bueno M, Gallegos M-T, Ramos J-L (2007) Optimization of the palindromic order of the TtgR operator enhances binding cooperativity. J Mol Biol 369:1188-1199. https:// doi.org/10.1016/j.jmb.2007.04.025

Lampe DJ, Akerley BJ, Rubin EJ, Mekalanos JJ, Robertson HM (1999) Hyperactive transposase mutants of the Himar 1 mariner transposon. Proc Natl Acad Sci 96:11428-11433. https://doi.org/10.1073/pnas. 96.20.11428

Li XZ, Klebensberger J, Rosche B (2010) Effect of $g c l, g l c B$, and aceA disruption on glyoxylate conversion by Pseudomonas putida JM37. J Microbiol Biotechnol 20:1006-1010. https://doi.org/10.4014/jmb. 0912.12005

Mars AE, Gorissen JPL, van den Beld I, Eggink G (2001) Bioconversion of limonene to increased concentrations of perillic acid by Pseudomonas putida GS1 in a fed-batch reactor. Appl Microbiol Biotechnol 56:101-107. https://doi.org/10.1007/s002530100625

Martínez-García E, de Lorenzo V (2011) Engineering multiple genomic deletions in Gram-negative bacteria: analysis of the multi-resistant antibiotic profile of Pseudomonas putida KT2440. Environ Microbiol 13:2702-2716. https://doi.org/10.1111/j.1462-2920. 2011.02538.x

Mi J, Becher D, Lubuta P, Dany S, Tusch K, Schewe H, Buchhaupt M, Schrader J (2014) De novo production of the monoterpenoid geranic acid by metabolically engineered Pseudomonas putida. Microb Cell Factories 13:1-11. https://doi.org/10.1186/s12934-014-0170-8

Mi J, Schewe H, Buchhaupt M, Holtmann D, Schrader J (2016) Efficient hydroxylation of 1,8-cineole with monoterpenoid-resistant recombinant Pseudomonas putida GS1. World J Microbiol Biotechnol 32: 112. https://doi.org/10.1007/s11274-016-2071-y

Mikkers H, Allen J, Knipscheer P, Romeyn L, Hart A, Vink E, Berns A (2002) High-throughput retroviral tagging to identify components of specific signaling pathways in cancer. Nat Genet 32:153-159. https://doi.org/10.1038/ng950

Mosqueda G, Ramos J-L (2000) A set of genes encoding a second toluene efflux system in Pseudomonas putida DOT-T1E is linked to the tod genes for toluene metabolism. J Bacteriol 182:937-943. https://doi. org/10.1128/JB.182.4.937-943.2000

Nelson KE, Weinel C, Paulsen IT, Dodson RJ, Hilbert H, Martins dos Santos VAP, Fouts DE, Gill SR, Pop M, Holmes M, Brinkac L, Beanan M, DeBoy RT, Daugherty S, Kolonay J, Madupu R, Nelson W, White O, Peterson J, Khouri H, Hance I, Lee PC, Holtzapple E, Scanlan D, Tran K, Moazzez A, Utterback T, Rizzo M, Lee K, Kosack D, Moestl D, Wedler H, Lauber J, Stjepandic D, Hoheisel J, Straetz M, Heim S, Kiewitz C, Eisen J, Timmis KN, Düsterhöft A, Tümmler B, Fraser CM (2002) Complete genome sequence and comparative analysis of the metabolically versatile Pseudomonas putida KT2440. Environ Microbiol 4:799-808. https://doi.org/10.1046/j.1462-2920.2002.00366.x

Otto M, Wynands B, Drepper T, Jaeger K-E, Thies S, Loeschcke A, Blank LM, Wierckx N (2019) Targeting 16S rDNA for stable recombinant gene expression in Pseudomonas. ACS Synth Biol 8: 1901-1912. https://doi.org/10.1021/acssynbio.9b00195

Papadopoulos CJ, Carson CF, Chang BJ, Riley TV (2008) Role of the MexAB-OprM efflux pump of Pseudomonas aeruginosa in tolerance to tea tree (Melaleuca alternifolia) oil and its monoterpene components terpinen-4-ol, 1,8-cineole, and a-terpineol. Appl Environ Microbiol 74:1932-1935. https://doi.org/10.1128/AEM. 02334-07

Pinkart HC, White DC (1997) Phospholipid biosynthesis and solvent tolerance in Pseudomonas putida strains. J Bacteriol 179:4219 4226. https://doi.org/10.1128/jb.179.13.4219-4226.1997

Poole K, Gotoh N, Tsujimoto H, Zhao Q, Wada A, Yamasaki T, Neshat S, Yamagishi J, Li X-Z, Nishino T (1996) Overexpression of the mexCmexD-oprJ efflux operon in $n f x B$-type multidrug-resistant strains of Pseudomonas aeruginosa. Mol Microbiol 21:713-725. https://doi. org/10.1046/j.1365-2958.1996.281397.x

Poole K, Krebes K, McNally C, Neshat S (1993) Multiple antibiotic resistance in Pseudomonas aeruginosa: evidence for involvement of an efflux operon. J Bacteriol 175:7363-7372. https://doi.org/10. 1128/jb.175.22.7363-7372.1993

Ramos JL, Cuenca MS, Molina-Santiago C, Segura A, Duque E, omezGarciá MR, Udaondo Z, Roca A (2015) Mechanisms of solvent resistance mediated by interplay of cellular factors in Pseudomonas putida. FEMS Microbiol Rev 39:555-566. https:// doi.org/10.1093/femsre/fuv006

Ramos JL, Duque E, Gallegos M-T, Godoy P, Ramos-González MI, Rojas A, Terán W, Segura A (2002) Mechanisms of solvent tolerance in gram-negative bacteria. Annu Rev Microbiol 56:743-768. https://doi.org/10.1146/annurev.micro.56.012302.161038

Ramos JL, Duque E, Godoy P, Segura A (1998) Efflux pumps involved in toluene tolerance in Pseudomonas putida DOT-T1E. J Bacteriol 180:3323-3329

Ramos JL, Duque E, Rodríguez-Herva JJ, Godoy P, Haïdour A, Reyes F, Fernández-Barrero A (1997) Mechanisms for solvent tolerance in 
bacteria. J Biol Chem 272:3887-3890. https://doi.org/10.1074/jbc. 272.7.3887

Ramos JL, Martínez-Bueno M, Molina-Henares AJ, Terán W, Watanabe K, Zhang X, Trinidad Gallegos M, Brennan R, Tobes R (2005) The TetR family of transcriptional repressors. Microbiol Mol Biol Rev 69:326-356. https://doi.org/10.1128/MMBR.69.2.326

Rau MH, Calero P, Lennen RM, Long KS, Nielsen AT (2016) Genomewide Escherichia coli stress response and improved tolerance towards industrially relevant chemicals. Microb Cell Factories 15: 176. https://doi.org/10.1186/s12934-016-0577-5

Rodríguez-Herva JJ, García V, Hurtado A, Segura A, Ramos JL (2007) The ttgGHI solvent efflux pump operon of Pseudomonas putida DOT-T1E is located on a large self-transmissible plasmid. Environ Microbiol 9:1550-1561. https://doi.org/10.1111/j.1462-2920.2007. 01276.x

Rojas A, Duque E, Mosqueda G, Golden G, Hurtado A, Ramos JL, Segura A (2001) Three efflux pumps are required to provide efficient tolerance to toluene in Pseudomonas putida DOT-T1E. J Bacteriol 183:3967-3973. https://doi.org/10.1128/JB.183.13.39673973.2001

Rojas A, Segura A, Guazzaroni ME, Terán W, Hurtado A, Gallegos MT, Ramos JL (2003) In vivo and In vitro evidence that $\mathrm{TtgV}$ is the specific regulator of the TtgGHI multidrug and solvent efflux pump of Pseudomonas putida. J Bacteriol 185:4755-4763. https://doi.org/ 10.1128/JB.185.16.4755-4763.2003

Schrader J (2010) Mikrobielle Oxidation von Monoterpenen. BioSpektrum 16:555-557

Schrader J, Bohlmann J (eds) (2015) Biotechnology of isoprenoids. Springer International Publishing, Cham

Segura A, Rojas A, Hurtado A, Huertas M-J, Ramos JL (2003) Comparative genomic analysis of solvent extrusion pumps in Pseudomonas strains exhibiting different degrees of solvent tolerance. Extremophiles 7:371-376. https://doi.org/10.1007/s00792003-0331-x

Shah AA, Wang C, Chung Y-R, Kim J-Y, Choi E-S, Kim S-W (2013) Enhancement of geraniol resistance of Escherichia coli by MarA overexpression. J Biosci Bioeng 115:253-258. https://doi.org/10. 1016/j.jbiosc.2012.10.009

Sikkema J, de Bont JA, Poolman B (1994) Interactions of cyclic hydrocarbons with biological membranes. J Biol Chem 269:8022-8028

Silby MW, Winstanley C, Godfrey SAC, Levy SB, Jackson RW (2011) Pseudomonas genomes: diverse and adaptable. FEMS Microbiol Rev 35:652-680. https://doi.org/10.1111/j.1574-6976.2011.00269. $\mathrm{x}$

Speelmans G, Bijlsma A, Eggink G (1998) Limonene bioconversion to high concentrations of a single and stable product, perillic acid, by a solvent-resistant Pseudomonas putida strain. Appl Microbiol Biotechnol 50:538-544. https://doi.org/10.1007/s002530051331

Terán W, Felipe A, Fillet S, Guazzaroni M-E, Krell T, Ruiz R, Ramos JL, Gallegos M-T (2007) Complexity in efflux pump control: crossregulation by the paralogues $\mathrm{TtgV}$ and $\mathrm{Ttg} \mathrm{T}$. Mol Microbiol 66: 1416-1428. https://doi.org/10.1111/j.1365-2958.2007.06004.x

Terán W, Felipe A, Segura A, Rojas A, Ramos J-L, Gallegos M-T (2003) Antibiotic-dependent induction of Pseudomonas putida DOT-T1E $\operatorname{Ttg} \mathrm{ABC}$ efflux pump is mediated by the drug binding repressor
TtgR. Antimicrob Agents Chemother 47:3067-3072. https://doi. org/10.1128/AAC.47.10.3067-3072.2003

Timmis KN (2002) Pseudomonas putida: a cosmopolitan opportunist par excellence. Environ Microbiol 4:779-781. https://doi.org/10.1046/j. 1462-2920.2002.00365.x

Seemann T (2014) Prokka: rapid prokaryotic genome annotation. Bioinformatics 30:2068-2069

Trombetta D, Castelli F, Sarpietro MG, Venuti V, Cristani M, Daniele C, Saija A, Mazzanti G, Bisignano G, Grazia M (2005) Mechanisms of antibacterial action of three monoterpenes. J Antimicrob Agents Chemother 49:2474-2478. https://doi.org/10.1128/AAC.49.6.2474

Udaondo Z, Duque E, Fernández M, Molina L, de la Torre J, Bernal P, Niqui J-L, Pini C, Roca A, Matilla MA, Antonia Molina-Henares M, Silva-Jiménez H, Navarro-Avilés G, Busch A, Lacal J, Krell T, Segura A, Ramos J-L (2012) Analysis of solvent tolerance in Pseudomonas putida DOT-T1E based on its genome sequence and a collection of mutants. FEBS Lett 586:2932-2938. https://doi.org/ 10.1016/j.febslet.2012.07.031

Uribe S, Ramirez J, Peña A (1985) Effects of $\beta$-pinene on yeast membrane functions. J Bacteriol 161:1195-1200

van Beilen JB, Holtackers R, Lüscher D, Bauer U, Witholt B, Duetz WA (2005) Biocatalytic production of perillyl alcohol from limonene by using a novel Mycobacterium sp. cytochrome P450 alkane hydroxylase expressed in Pseudomonas putida. Appl Environ Microbiol 71:1737-1744. https://doi.org/10.1128/AEM.71.4.1737-1744.2005

Vidal-Aroca F, Meng A, Minz T, Page MGP, Dreier J (2009) Use of resazurin to detect mefloquine as an efflux-pump inhibitor in Pseudomonas aeruginosa and Escherichia coli. J Microbiol Methods 79:232-237. https://doi.org/10.1016/j.mimet.2009.09.021

Wang Q, Nomura CT (2010) Monitoring differences in gene expression levels and polyhydroxyalkanoate (PHA) production in Pseudomonas putida KT2440 grown on different carbon sources. J Biosci Bioeng 110:653-659. https://doi.org/10.1016/j.jbiosc.2010. 08.001

Wang Y, Lim L, DiGuistini S, Robertson G, Bohlmann J, Breuil C (2013) A specialized ABC efflux transporter GcABC-G1 confers monoterpene resistance to Grosmannia clavigera, a bark beetle-associated fungal pathogen of pine trees. New Phytol 197:886-898. https://doi. org/10.1111/nph.12063

Weidner U, Geier S, Ptock A, Friedrich T, Leif H, Weiss H (1993) The gene locus of the proton-translocating NADH:ubiquinone oxidoreductase in Escherichia coli. J Mol Biol 233:109-122. https://doi. org/10.1006/jmbi.1993.1488

Wijte D, van Baar BLM, Heck AJR, Altelaar AFM (2011) Probing the proteome response to toluene exposure in the solvent tolerant Pseudomonas putida S12. J Proteome Res 10:394-403. https://doi. org/10.1021/pr100401n

Wu X, Monchy S, Taghavi S, Zhu W, Ramos J, van der Lelie D (2011) Comparative genomics and functional analysis of niche-specific adaptation in Pseudomonas putida. FEMS Microbiol Rev 35:299323. https://doi.org/10.1111/j.1574-6976.2010.00249.x

Publisher's note Springer Nature remains neutral with regard to jurisdictional claims in published maps and institutional affiliations. 